\title{
Teaching
Methods
}

\section{The Writing Portfolio as a Tool for the Development of Communication and Learning Skills}

\author{
Paul Holford, ${ }^{1,3}$ Robert Ellis, ${ }^{2}$ \\ and Anthony Haigh ${ }^{3}$
}

\begin{abstract}
AdDitional INDEX WORDS. communication, education, literacy, writing
\end{abstract}

Summary. To improve the communication skills of students studying horticulture, collaboration between the subject lecturers and an academic skills consultant has led to the inclusion of a writing portfolio into the curriculum of Plant Science and Physiology, a core science component of the Bachelor of Horticultural Science program. The rationale for the portfolio was that, through writing, students would engage more closely with a subject's content and would gain a better understanding of its concepts. The initiatives introduced into the portfolio include the

The cost of publishing this paper was defrayed in part by the payment of page charges. Under postal regulations, this paper therefore must be hereby marked advertisement solely to indicate this fact.

${ }^{1}$ Centre for Horticulture and Plant Sciences.

${ }^{2}$ Centre for Higher Education Development, Univer sity of Western Sydney, Locked Bag 1797, South Penrith Distribution Centre, NSW 1797, Australia.

${ }^{3}$ To whom reprints should be addressed. development of nine writing portfolio tasks and model answers, an appropriate grading tool and the integration of the writing tasks into other assessment tools. The focus on writing simultaneously improved students' awareness of the standard and type of writing expected at university, allowed them to develop their written expression, and deepened their understanding of plant science.

$\mathrm{T}$ he University of Western Sydney (UWS) was created to overcome the underprovision of opportunities for people in greater Western Sydney to study at university (Reid, 1999). This region has an over-representation of people with low socio-economic status and with language backgrounds other than English compared to national averages. It is part of the university's mission to target these groups, thereby providing access for students whose families have had little contact with university education. Consequently, although many of the students enrolling at UWS are keen and committed to their study programs, many lack the literacy skills to do well. Therefore, to enable students both to succeed at university and in the workplace, it is imperative that the development of communication skills becomes part of the university's curricula.

At an international level, the development of written communication skills in university curricula has been helped by writing across the curriculum (WAC) programs (McLeod and Soven, 1992). The approach in such programs is to facilitate the use of writing as a way of learning through broadening, deepening and clarifying a student's knowledge. In comparison with the WAC movement in North America, which has been operating since the mid-seventies, in Australia the use of writing as a way of learning has not been taken up with the same enthusiasm. This is despite the fact that the ability to communicate is one of the most important attributes an Australian university should aim to develop in its graduates (Andersen, 1995; Cappelletto, 1993; Higher Education Council, 1992; Ramsden 1992). In scientific subjects, for example, significantly less attention has been paid to communications skills as an integral part of most curricula (Holford et al., 1999). The reasons for this may lie in three areas. Firstly, in the past, only a small proportion of the population attended university. This group is likely to have consisted of elite students with good communication skills; therefore, there was little need for improvement. Secondly, changes in teaching methods in secondary schools seem to be producing students with poorer levels of literacy (Hampton, 1998). Lastly, university lecturers involved in science subjects may not see the provision of communications skills as either their role or responsibility, or may feel they lack the resources necessary to develop these skills.

One approach to the development of communication skills is through the introduction of foundation programs that specifically concentrate on this area. Within the curriculum of the Bachelor of Horticultural Science program offered by UWS, the course Plants in Society (PiS) was introduced. This course aims to develop students' learning and literacy through exercises designed to practice academic reading, writing and analytical skills. However, a potential problem with this type of course is a lack of interest from the students who cannot see its relevance. Therefore, both the teaching method and the course content need to be adjusted to a particular audience and discipline (Wilcox, 1980): this is considered to be the first principle of good course design (Marshall and Williams, 1986). In PiS, student engagement is achieved by subject matter that highlights the importance of plants, their numerous uses throughout history and their role in the development and functioning of today's society.

Although the introduction of 
foundation subjects such as PiS is necessary for the enhancement of communication skills, single subjects have not always produced improvements in academic performance (Ramsden et al., 1986; Norton and Crowley, 1995). Rather, improvement appears to be a slow, progressive process (Norton and Crowley, 1995) and requires constant development throughout a degree program (Kemp and Seagraves, 1995). To help maintain this development in the Batchelor Horticultural Science program, a writing portfolio has been introduced into the curriculum of Plant Science and Physiology (PSP). This initiative is the result of a collaboration between scientists and educational developers at UWS, an approach to the inclusion of communication components into curricula that is becoming more prevalent (Holford et al., 1999; Webb et al., 1995) and a collaboration shown to be successful in North American universities (VaughtAlexander, 1999). Such initiatives are also necessary because of the absence in Australia of support systems such as the TRIO programs (Council for Opportunity in Education, 2000) in the United States that aim to help students overcome class, social and cultural barriers that might prevent their entry into and continuation with higher education.

\section{The learning context surrounding the writing portfolio}

The content of PSP forms the foundation for higher-level, sciencebased subjects as well as those that are more practically orientated and, as such, is a core subject. It is designed to enable students to understand fundamental processes involved in plant growth, focuses on processes at the cellular and whole plant level, and provides students with an understanding of how the genetic potential of plants is modified by environmental factors.

Students studying PSP have traditionally found the subject difficult, and although a significant percentage of students are enthusiastic and recognise its value and relevance, an increasing percentage displays insufficient written language skills to perform well. Students find PSP challenging because it is science-based and consequently content-heavy. And, as many do not have a science background, they find the content difficult, especially as the subject requires knowledge of a specialised lexicon and often deals with abstract ideas. In addition, often being the first in their families to attend university, many students are not aware of the standards required for the successful completion of subjects. Compounding this last problem are inadequate English skills and problems with expression of ideas and arguments. To help address the needs of the learning context, a writing portfolio was introduced into the curriculum of PSP.

The portfolio was first introduced during the first semester of 1999 by the science lecturers responsible for the subject and a learning lecturer. In that semester, there was an enrollment of about 70 students. The two science lecturers were responsible for the delivery of course content and grading, and providing individual feedback on the portfolio tasks. To ensure that students perceived the monitoring of the implementation of the portfolio to be separate from their assessment, the learning lecturer was responsible for the focus group sessions (two 15-min sessions during the semester), for interviews with individual students, and for the administration of subject monitoring questionnaires. In addition, the learning lecturer also gave two 2 -h workshops and weekly tutorials covering general feedback resulting from the portfolio tasks or focus groups sessions (both about $15 \mathrm{~min}$ ) during the beginning of the laboratory practicums.

\section{Aims and rationale of the writing portfolio}

To maximise the impact of the portfolio and to address the needs of the learning context, a set of tasks was designed that had the following aims:

- To encourage a greater understanding of subject content through integrating material learned through lectures, tutorials, practicals, video presentations, use of study guides, self-assessment tasks and personal study.

- Tohelp students develop and comprehend a scientific lexicon.

- To improve the students' ability to discuss abstract ideas and concepts.
- To help students develop strong written communication skills that will support them in both the remainder of their study and their ventures in the workforce.

- To foster positive student attitudes towards the development of science, writing and study skills.

The pedagogical rationale behind the portfolio design was to use writing for both expressive and transactional purposes. Expressive purposes are those that clarify understanding to the writer through the process of writing, and transactional purposes are those that clarify the understanding of the writer to another audience (McLeod, 1999). Therefore, as proposed by Herrington (1981) and Jackson (1991), through writing, students engage closely with the subject content, enabling them to clarify their understanding of the topics of PSP. The lecturers also felt confident that students, by engaging in writing the portfolio tasks regularly, would develop the necessary skills to allow them to succinctly express their understanding of the science-based content of courses such as PSP. In addition, the use of multiple portfolio tasks should gradually develop a student's awareness of the standard and quality of the scientific discussion that is expected of a particular discourse community (Hirvela, 1997).

Writing as a means of learning may help students develop a positive approach to the subject (HarringSmith, 1992). The use of annotated student texts (examples of good and bad writing) to assist students in their writing tasks often allows them to develop a sense of ownership over learning and helps to ensure that the aims of portfolios are achieved (Quattrini, 1996). These outcomes would also help to improve student confidence and reduce the anxiety often associated with studying content-heavy subjects in the first year of university.

\section{The design process}

The design of the portfolio started with a review of the existing assessment system. The components of the previous system included four minor tests, an essay of about 2000 words and a final exam consisting of three essays. Each of these assessment tools was considered with respect to the types of responses students were required to produce. The minor tests typically made use of multiple-choice 


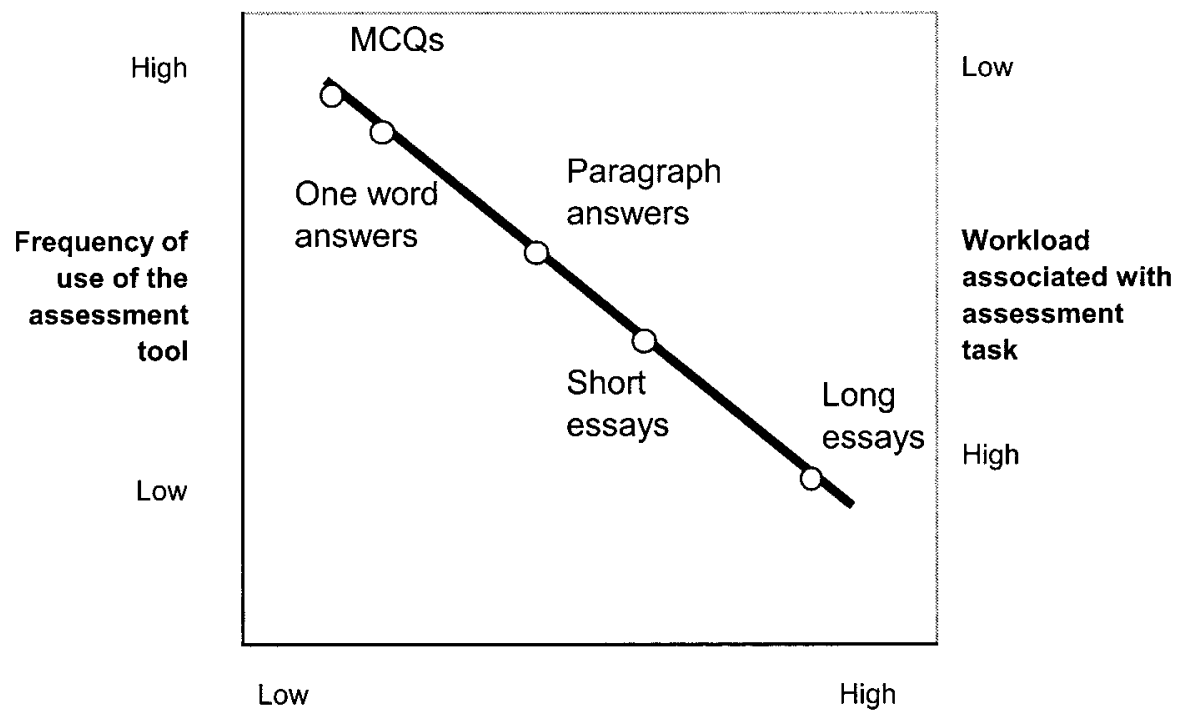

Evidence of learning provided by the assessment tool

Fig. 1. The relationship between the likely frequency of use of assessment tools, their potential to provide evidence of learning and their ease of assessment. MCQ $s=$ multiple choice questions.

questions (MCQs), true/false and oneword answers. It became clear from this review that the academic literacy skills needed by students to complete the minor tests were light compared to those required in the rest of the assessment system. This meant that the types of assessment questions in the minor tests were not providing students with sufficient opportunities to improve their written communication skills and were not addressing the development of discipline-specific literacy. Additionally, the MCQs and one-word answers of the minor tests were not providing the lecturers with sufficient evidence of the knowledge and stage of student development. At best, they revealed which students were doing well in the subject. However, for those students who were not succeeding, the responses required by the minor tests did not reveal the reasons for their lack of success.

While reviewing the assessment system, the important characteristics of the assessment tasks were appraised in two ways. Firstly, the lecturers felt that each task should reveal as much as possible about the stage of learning reached by a student; secondly, each task should lend itself to efficient marking and rapid feedback. In the original assessment, one-word answer questions were preferred as they could be graded and returned quickly; however, they actually revealed little about a student's understanding of the subject. Essays provided the most infor- mation about a student's ability to comprehend, compare, analyze and synthesise subject content but take too long to grade. The lecturers believed that paragraph/short essay answers of around 200 to 400 words would reveal sufficient information about a student's understanding and could be used to continuously monitor his/her development, while not requiring a disproportionate amount of marking time. The relationship between the ease of assessment, value as an assessment tool and likely frequency of use of different assessment tasks is expressed in Fig. 1.

In addition to the review of the type and content of the tasks of the assessment system, the dates on which they were due were also revised. Under the previous assessment system, the first piece of assessed work requiring a substantial written text was not submitted until Week 10, with feedback given in Week 11 of a 13 -week semester. While other assessments were handed back by Week 5 , they did not require the students to produce a significant amount of written work. The lecturers felt that receiving the first substantial piece of written work from the students in Week 10 was too late in the learning process to allow improvement of any weaknesses. In the new assessment scheme, the earliest due date of the first piece of written work permitted feedback by Week 3 with feedback from subsequent tasks coming at weekly intervals. It was expected that early and regular feedback would be more likely to encourage students to continuously reflect on their writing skills throughout the semester.

\section{The writing portfolio tasks}

The tasks of the writing portfolio are presented in Table 1 . The tasks, by design, progressed from the relatively simple to the more academically demanding. This was achieved, firstly, in terms of length, with the tasks graduating from single sentence answers to those requiring linked paragraphs. Secondly, the academic content also increased throughout the portfolio. The first few tasks only required students to display a knowledge and comprehension of appropriate content, while latter tasks required more demanding thought processes such as analysis, synthesis, and evaluation as defined by Bloom (1956) and Biggs (1999). The simplicity of the initial tasks allowed students to gain a feeling of achievement through the successful completion of tasks with a high scientific content and so promote the completion of subsequent ones.

An important feature of the writing portfolio tasks is their potential to provide a means of integrating all parts of the teaching and assessment system (Fig. 2). The writing tasks were designed so that the students had to write about scientific concepts that are important for the minor tests and final exam. This is significant for two reasons. Firstly, it ensures that students engage with the content of the assessment tasks at a written level and that they have received feedback on their efforts from the lecturers. Secondly, it emphasises to them the relevance and importance of completing the writing portfolio tasks. The integration of the writing portfolio into the assessment system had a positive impact on the design of other parts of the assessment system. Given the quality of insight into the students' stage of learning provided by the writing portfolio tasks, the lecturers wanted to replicate this characteristic in the minor tests. Therefore, the minor tests were redesigned to incorporate paragraph-answer questions of about 250 words. This congruency between the tasks and the minor tests requires the students to put in a consistent effort throughout the semester, rather than cramming at the end. In addition, the increasing demand on a student's writing ability 
as the semester progresses, coupled with tutorials and feedback on their writing tasks, requires students to work on their writing skills. This helps them to successfully complete the essays in their final examination.

\section{Feedback and assessment}

Another important element of the portfolio design process was monitor- ing the progress of each student closely. By grading a student's work and providing regular feedback, both lecturers and students shared an understanding of the learning development of an individual from one writing task to the next. The tasks of the portfolio also made explicit to students the standards expected by the lecturers, both in terms of content and writing ability.
Feedback was given to students one week after submission, as clear and timely feedback is most likely to have the greatest impact on a student's writing process and any suggested changes in their writing style can be incorporated into subsequent tasks. In addition to the grade, direct feedback was given as comments on each manuscript regarding language, organiza-

Table 1. Tasks of the writing portfolio incorporated into plant science and physiology. Task foci are taken from Bloom (1956) and Biggs (1999).

\section{Task and focus Content and purpose}

1. Summarizing

2. Summarizing

3. Explaining, describing

4. Discussing

5. Analyzing

6. Reporting, analyzing

7. Reviewing

8. Summarizing

9. Analyzing genome.
This consists of a letter to an imaginary sick friend explaining the content of the first two lectures. The students are told that the body of the letter should consist of three paragraphs of about 10 lines each: the first about cells and life; the second discussing cell membranes; and the third explaining the constituents of plant cells. This exercise is unmarked and provides diagnostic from which improvements in writing skills can be judged. It also reinforces the need for good note taking during lectures.

In the second task, students write short paragraphs on the contributions made to plant science by nine scientists (e.g., Aristoltle, Van Helmont, Glauber and Woodward). This task aims to get students to turn lecture notes into sentences that are correct both in terms of ideas and English usage, to link sentences together so that they produce a coherent paragraph, and to research a topic. The task also illustrates the use of chronology as a means of structuring a piece of text.

This exercise follows from an imaginary response to the letter sent in Task 1 with students replying to questions posed by the recipient (e.g., why does grass seem cool compared to concrete even though both are exposed to same amount of sunlight and how is it possible to use water to prevent frost damage). This task again requires the students to write coherent paragraphs and is used to illustrate the depth and comprehensiveness of written work required at university.

In Task 4, students are asked to discuss three possible reasons for the development of agriculture and decide which one is most likely. This exercise requires students to present sufficient information on which a person reading the task could base a decision. In addition, the students have to decide which facts support or contradict each theory and then form a logical argument to defend the one they have chosen. The exercise again emphasises the importance of good note taking.

In this task, students are asked to explain the relationships between certain features of the genetic apparatus of plant and animal cells (e.g., between genes and chromosome, bases and nucleotides or chromosomes and genomes). Once they have completed this, they are asked to draw a diagram that would indicate the different structural levels of a genome to a student learning genetics. Our students have problems with any part of the syllabus related to chemistry and by describing the components of DNA, genes, chromosome and genomes in their own words, they gain a greater comprehension of this aspect of genetics. This task is also designed to improve the students' analytical skills through the deconstruction and reconstruction of an organism's

This task is based on a practical workshop introducing Mendelian ratios. The students are asked to outline the experimental procedures, explain why they were performed, describe the results obtained and contrast them with those found by Gregor Mendel. This task integrates practical work with theory sessions and is intended to develop an understanding of experimental design. It also introduces the genre of the research article through explaining experimental procedures and drawing conclusions from a set of results.

Task 7 requires students to review the material from the modules of plant science and physiology on molecular and transmission genetics. Once they have familiarised themselves with this material, they are asked to write about the causes of variation found in plant and animal species. This task introduces students to the genre of review articles and requires them to organize information in a logical sequence. It also gives students the opportunity to demonstrate mastery of sentence and paragraph construction.

In Task 8, students are asked to draw a series of labelled diagrams that show the processes of light harvesting and energy conversion during photosynthesis. They are then provided with a series of key words that they must include in written descriptions of the operation of these processes. The first part of this task provides students with a visual representation of photosynthesis to help with their comprehension of this topic. The second part requires students to clarify their understanding of photosynthesis by again summarising chemical concepts in words. The exercise is also useful in clarifying the detail required for degree level answers.

The last task compares and contrasts the physiological processes thought to be involved in the control of flowering. This task again challenges students' analytical skills and requires them to identify commonalities and differences in key features of these processes. 


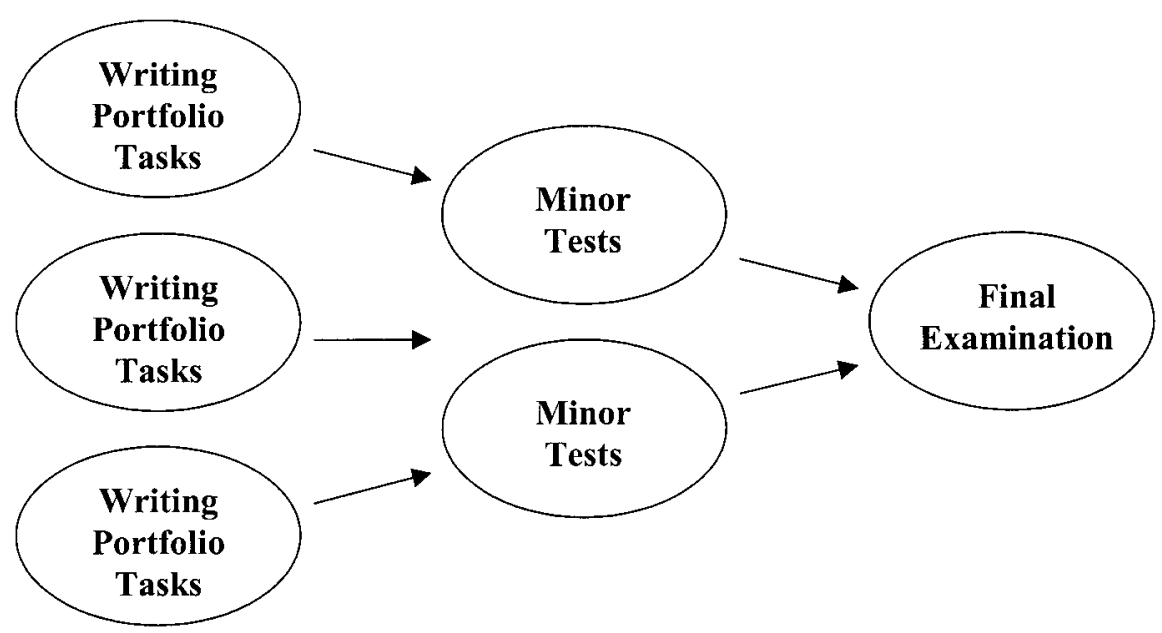

Fig. 2. The relationship between the content and literacy skills required to complete the assessment tasks of plant science and physiology.

tion and scientific content, where improvement could be made or corrections were necessary. For the cohort of 70 students, the grading and feedback of each task took about 1 to 2 working days, giving about 6 working days of assessment per lecturer. However, the tasks to be assessed by each of the lecturers were spread throughout the semester; therefore, the assessment process was not too onerous. Comments to individuals were supplemented by indirect feedback provided through tutorials on language usage designed by the specialist in educational development. During these tutorials, model answers and examples of student writing of different standards were discussed with the group. This information allowed students to assess their level of performance against other students within their cohort and with that required at university. The material in the tutorials allowed both scientific content and common problems with English usage (such as poor sentence/paragraph construction or noun/verb agreements) to be clarified. As the material used in these tutorials came largely from student answers, students could see the direct relevance of the feedback to their studies.

\section{Outcomes of the implementation of the portfolio}

One aim of the teaching intervention was to clarify what occurred when the portfolio was embedded in the curriculum of PSP. Insights into the impact of the portfolio on student learning processes were gained from individual interviews, focus group interviews, informal student comments, surveys and data provided by the portfolio itself such as the grading system.

Individual interviews conducted at the beginning of the term revealed a variety of attitudes towards the writing portfolio tasks. Comments from some students showed that they were initially amazed that writing was valued within a science subject:

“...What are you telling me about my writing for? This is a joke. You expect this sort of stuff in an English class. We already know about this. Why are we doing it in PSP? If I wanted to know about this sort of stuff, I would have enrolled in Arts..."

Other students thought that science was about learning facts and did not understand that writing was important in order to clarify and reveal their understanding:

"...Why do we have to do these tasks? It would be better if you taught us more about the content. I want to spend more time learning about scientific facts. The writing tasks take away time from tuition about content. Why do I have to write well to learn about PSP? As long as I know it, then that's enough..."

By the end of the semester, attitudes to the writing tasks had changed. Anonymous questionnaires were given to the students during the semester and early in the subsequent semester: more than $90 \%$ of students returned completed questionnaires on both occasions. These showed that $77 \%$ of the students recognised that writing was as important for their future career as knowing scientific content. Furthermore, about $60 \%$ of students felt that the tasks had improved their writing skills, most of the remainder being neutral. Half of the students agreed that the tasks had helped them to learn and understand the subject content (one third was neutral). Also, a majority of students felt that the tasks had helped them to write better in other subjects. A positive outcome from the portfolio was the request by several students for similar tasks to be incorporated into the curricula of their other subjects.

The opinions expressed in the survey confirmed the perceptions of the lecturers coordinating the subject who, in interviews about the collaboration, also thought that the general level of organization and expression of the students' written work had improved during the semester. These outcomes are similar to those found in some Australian studies. One such study investigated the impact of the introduction of writing tasks based on written genres found within science into a first-year, biological science curriculum (Taylor and Drury 1996). This study concluded that as a result of the introduction of the scientific writing tasks into the curriculum, some students had developed more mature learning strategies and changed their conception of learning, which had, in turn, led to a better understanding of the content.

The results of the students studying PSP were analyzed to assess how they had progressed in the subject. The students were divided into two groups based on their final grade for the subject, and the improvement of the groups over the semester was compared. This analysis showed that the average increase in grade for those students with final marks in the top of the cohort was about the same as that of students in the lower half of the cohort ( $15 \%$ to $20 \%$ improvement in each group); while it is difficult to attribute all of this improvement to the portfolio because of the other variables in the learning context, it appears that both groups benefited. This is not to say that all writing problems had disappeared. Both groups of students still displayed problems with expression. This observation underlines the need, identified by Kemp and Seagraves 
(1995), for communication skills to be foregrounded and developed throughout a degree program. The deficiencies identified will be addressed in future versions of the portfolio through additional approaches addressing the wide range of problems existing in the literacy skills of our students.

Our experience has shown that the writing portfolio offers an efficient way by which improvements in the learning of science students can be made visible. The portfolio can be easily embedded in the curriculum of any subject without either costing too much time in the form of lecturer input nor making a substantial increase in the students' work load. Also, the many tasks offer ample opportunity to give individualised feedback so that any deficiencies in a particular student can be addressed. The writing portfolio provides both a means of preparing students for other assessment tasks and also forms an efficient assessment tool in its own right. In PSP, the writing portfolio was used for both purposes as it prepared the students for their minor tests and final exam and the tasks themselves were assessable, forming $20 \%$ of a student's final mark. In addition, the experience has suggested that the more lecturers help students to write about their understanding of science, the more learning the students display. Furthermore, from the lecturers' perspective, the students' writing portfolios make it easier to gauge how much students know and on what areas to focus to ensure quality learning.

\section{Literature cited}

Anderson, R.D. 1995. Science, technology and education-The challenge to education. Agr. Sci. 8:37-40.

Biggs, J. 1999. Teaching for quality learning. Soc. Res. Higher Educ. Open Univ. Press, Buckingham, UK.
Bloom, B.S. (ed.). 1956. Taxonomy of educational objectives: The classification of educational goals. Handbook I: Cognitive domain. David McKay, New York.

Cappelletto, G. 1993. Educating chartered accountants. In: Accounting above and beyond. Proc. Annu. Meeting Accounting Assn. Austral. and N.Z., Darwin, Australia.

Council for Opportunity in Education. 2000. Bringing diversity and opportunity to America's colleges and universities. 3 July 2001 . <http://www.TRIOprograms. org.>

Hampton, J. 1998. Developing science students' writing skills. Agr. Sci. 11:3334 .

Haring-Smith, T. 1992. Changing students' attitudes: Writing fellows programs, p. 175-188. In: S.H. McLeod and M. Soven (eds.). Writing across the curriculum. Sage Publ., Newbury Park, Calif.

Herrington, A.J. 1981. Writing to learn: Writing across the disciplines. College English 43:379-387.

Higher Education Council. 1992. Achieving quality. Natl. Board of Employment, Educ. and Training, Australian Govt. Pub1. Serv., Canberra.

Hirvela, A. 1997. Disciplinary portfolios and EAP writing. English for Specific Purposes 16:83-100.

Holford, P., C. Webb, J. Malfroy, and J. Conroy. 1999. Enhancing the research competencies of horticulture graduates through improved communications skills. HortTechnology 9:267-272.

Jackson, M.W. 1991. Writing as learning: Reflections on developing students' writing strategies. Higher Educ. Res. Dev. $10: 41-52$.

Kemp, I.J. and L. Seagraves. 1995. Transferable skills-Can higher education deliver? Studies in Higher Educ. 20:305314.

MacKay, B.R., L. Emerson, M.B. MacKay, K.A. Funnell, and T.E. Welsh. 1999. Challenging the pedagogy of tertiary level horticulture. HortTechnology 9:272-276.
Marshall, S. and N. Williams. 1986. Exercises in teaching communication. Kogan, London.

McLeod, S.H. 1992. Writing across the curriculum: An introduction. p. 1-11. In: S.H. McLeod and M. Soven (eds.). Writing across the curriculum. Sage Publ., Newbury Park, Calif.

Norton, L.S. and C.M. Crowley. 1995. Can students be helped to learn how to learn? An evaluation of an approach to learning program for first year degree students. Higher Educ. 29:307-328.

Quattrini, J.A. 1996. Hearing voices: Colleagues in the classroom. English J. 85:6266.

Ramsden, P. 1992. Learning to teach in higher education. Routledge, London.

Ramsden, P., D.G. Beswick, and J.A. Bowden. 1986. Effects of learning skills interventions on first year university students' learning. Human Learning 5:151164.

Reid, J. 1999. The shape of the future-A structure for UWS in the $21^{\text {st }}$ century. 14 Aug. 2000. <http://www.uws.edu.au/ html/shape_of_the_future.pdf.>

Taylor, C. and H. Drury. 1996. Teaching writing skills in the science curriculum, $\mathrm{p}$. 864-869. In: Different approaches: Theory and practice in higher education. Proc. $19^{\text {th }}$ Higher Educ. Res. Dev. Soc. Australasia Conf., Perth, Australia.

Vaught-Alexander, K. 1999. Situating writing centres and WAC programs in the academy: Creating partnerships for change with organizational development theory, p. 119-140. In: R.W. Barnett and J.S. Blumner (eds.). Writing centers and writing across the curriculum programs.

Webb, C., E. English, and H. Bonanno. 1995. Collaboration in subject design: integration of the teaching and assessment of literacy skills into a first-year accounting course. Accounting Educ. 4:335-350.

Wilcox, S.W. 1980. Communication courses for engineering students. Eng. Educ. 70:750-752. 